\title{
EFFECT OF HUMAN FACTOR PERFORMANCE ON THE PRODUCTIVITY OF A MANUAL ASSEMBLY LINE
}

\author{
Vilela, F. F.*; Leal, F.*; Montevechi, J. A. B. ${ }^{*} \&$ Piedade, D. D. C. ${ }^{* *}$ \\ * Institute of Production Engineering and Management, Federal University of Itajubá, Itajubá, Brazil \\ ** Institute of Exact and Applied Sciences, Federal University of Ouro Preto, João Monlevade, Brazil \\ E-Mail: flavaofraga@unifei.edu.br, fleal@unifei.edu.br, montevechi@unifei.edu.br, \\ diego.piedade@aluno.ufop.edu.br
}

\begin{abstract}
To improve the reliability of the discrete event simulation model, it is necessary to represent, the best way possible, the operator behaviour and his subsequent performance. Deterministic simulation models often overestimate the production capacity of manufacturing systems since they don't consider some key relationships, such as the impact of human factor performance on productivity. This paper, with the aid of statistical techniques, analyses the total of boards produced, taking into consideration different periods of work shifts to apprehend the variability of human performance at different points throughout the day. Therefore, this paper aims to investigate the impact of human performance on the work shift and, hence, on the computer model's validity. Results reveal that human performance has a significant impact on the productivity of the assembly line investigated and affected the reliability of production forecasts through stochastic simulation.

(Received in February 2020, accepted in June 2020. This paper was with the authors 1 month for 1 revision.)
\end{abstract}

Key Words: Discrete Event Simulation, Human Factor Performance, Manual Assembly Line, Simulation Model Reliability

\section{INTRODUCTION}

The discrete event simulation (DES) is an assertive summary of a real system to generate inferences about it, thus avoiding the costs resulting from real experimentation and interrupting the flow of activities of this modelled system $[1,2]$. In fact, DES has been increasingly used as a basic tool to support decision making [3]. However, it is noteworthy that when a system is composed of numerous manual or semi-automatic activities, mainly depending on human factors for its realization, the discrete event simulation cannot accurately apprehend all points of interest in the system that was modelled and therefore, the simulation results may not be reliable [4]. This lack of reliability of the outputs of the computational model will therefore affect, in a greater or lesser extent, the validation of the computational model. One of the details that cannot be overlooked is related to the variability of performance of the human factor, because, according to [5], the performance of workers changes during the execution of tasks. Such change can occur between different specialists or operators who perform the same task or when the same specialist or operator redoes a task.

There are several variables (e.g., sleep time, age, temperature) that can be related to this variability in human factor performance. Sleep deprivation results, for example, in impaired reaction time, lengthy decision making and slow cognitive processing [6-12]. Thus, it is possible and likely that there are several impacts on the performance of the human factor due to only one variable, such as the lack of adequate sleep. Considering that innumerable variables can affect the human factor, we realize how much the operator is subject to random fluctuations in his general work performance.

Therefore, it is imperative to think of strategies to consider this human factor in the best possible way in computer simulation projects and to recognize the importance of capturing these factors during the DES project. In this context, the objective of this article is to investigate 
and understand the impact of the variation of the performance of the human factor on the productivity of the modelled system through a non-parametric statistical test to validate the computational model.

Thus, it will be verified whether the total simulated quantity of plates produced at the end of the electronic manual assembly line undergoes statistically significant changes when considering the variation in the performance of the human factor at different times of the day, varying the time of execution of the tasks in a stochastic manner.

To implement the objective of this article, an electronic board assembly line with four assembly steps was defined as the object of study. A discrete event simulation project was planned for this research, in which different seven scenarios were defined. Finally, the work is organized as follows: Section 2 presents the methods used for DES; Section 3 describes the experimental research to test the methodology; Section 4 provides the results and discussion; and Section 5 gives the conclusions along with the limitations of the work, plus guidelines for future research.

\section{MATERIAL AND METHODS}

The stages of a simulation project are shown in Fig. 1. In the first stage (conception), the model within the analyst's mind should be represented according to a simulation model representation technique (e.g., IDEF-SIM proposed by [13]) to make it a conceptual model, so that other individuals can understand it. The input data should also be collected at this first stage, being very important to know the correct probability distributions of fundamental stochastic processes that conduct the simulation [14]. In the stage called implementation, the second one, the conceptual model is then converted into a computer model through the implementation in a computer, using a simulation language or a commercial simulator. In this research we used the ProModel ${ }^{\circledR}$ software. Next, the computer model must also be checked against the conceptual model to determine if it is operating as expected. Some results should be generated to validate the computer model, from which it should be observed whether the model is an appropriate representation of reality. Techniques proposed by [15] and [16], such as comprising validation by model animation, validation by comparing the results provided by the model with the results obtained in the actual system through statistical tests and face-to-face validation are some possible options to carry out the validation of the computational model. Finally, it is important to emphasize that computational validation must be done carefully and following a rigorous assessment [17].
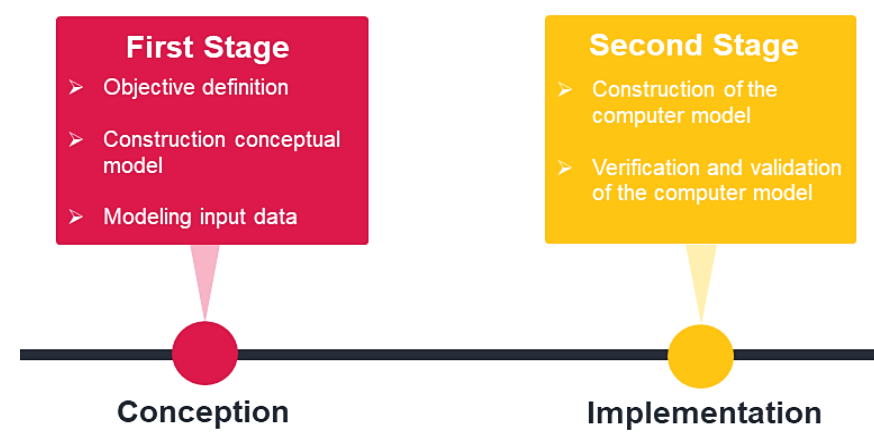

Third Stage

Execution of experiments

Statistical analysis

Conclusions

Conctusions

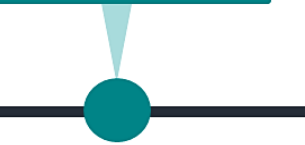

Analysis

Figure 1: Sequence of steps for simulation; adapted from [13].

In the third stage (analysis), after being verified and validated, the computer model is ready for the experiments, yielding the experimental model. Thus, the analysis phase consists of planning, executing and analysing experiments, and, at this stage, the design of experiments (DOE) techniques may be applied, as well as hypothesis tests [18]. After analysing the results, the conclusions and recommendations are presented. 
According to [19], the behaviour of an operator can be influenced by many factors such as the work surroundings (physical: micro-climate, noise, ergonomic factors; social: communication among the group, human relations), nature of the assignment (motor or cognitive, repetitive or non-repetitive, discrete or continuous) and personal factors (psychophysical attitudes, personal ability, gender, age). According to these authors, these factors can profoundly affect the conduct of an operator, which can ensue in performance variability amid the work shift. This changeability in task completion times can be observed in cases where the assignment is completed by the same operator in different production contexts and if the assignment is performed within the same work environment (physical and social environment). Sena et al. [20] state that in addition to the logical, analytical and computational aspects, human aspects must be studied and receive appropriate attention to their application. For [21], any service industry involves human members whose behaviour can influence system performance. Even the manufacturing industry, which has many automated systems, also involves the human being at some point. For [22], DES in its traditional approach does not adequately represent the human factor and its intrinsic aspects, thus impacts on productivity not predicted by the simulation will be noticed.

According to [23], the understanding and modelling of the behaviour of human factors in an uncertain and complex environment are tremendously challenging activities. Researchers from several fields have been putting substantial efforts to address this challenge and some attempts were made, like the work of Spencer [24] who modelled the correlated work performance with circadian rhythm.

The novelty of the research is to draw attention to the importance of human factors in a DES project using productivity as a quantitative metric. Applying a research on the Scopus ${ }^{\circledR}$ database using the terms "discrete-event simulation" and "human factor", while limiting the search to title, abstract and keyword, it is demonstrated in Fig. 2 that there is a growth in the number of works published in the last 11 years. However, the total number of 54 publications in the last 11 years considered is still incipient. Based on these results, the importance of this work is to expand the frontiers of knowledge regarding the human factor and DES using a quantitative metric.

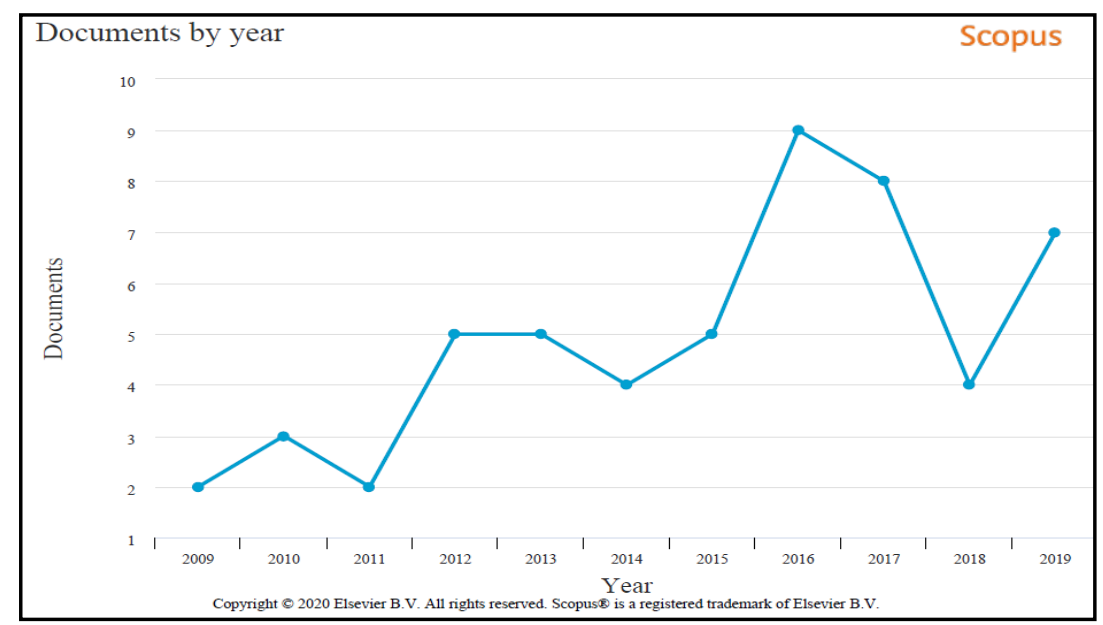

Figure 2: Research on the Scopus ${ }^{\circledR}$ database using the terms "discrete-event simulation" and "human factor"; last 11 years.

\section{APPLICATION OF THE METHOD}

After defining which human factor will be analysed, it is possible to determine the model within the method proposed by [25] and replicated by [26]. The object of the study of this paper was a manual assembly line that sets up electronic boards and works with high-volume production 
in a medium-sized company. This assembly line uses a straight layout with four sequenced steps. According to Fig. 3, step 1 refers to the review of the electronic board; step 2 is a touchup; step 3 is for testing; and step 4 is for packaging. Among the steps are the work-in-process $(W I P)$. Each step requires an operator to carry out the activity. This task is always accompanied by specific instructions $(F p)$.

Note that the conceptual model of the production process shown in Fig. 3 was conceived using the IDEF-SIM technique. The work shift hours are between 7:00 am and 5:00 pm, including a break for lunch between 12:00 noon and 1:00 pm and two stops for workplace gymnastics.

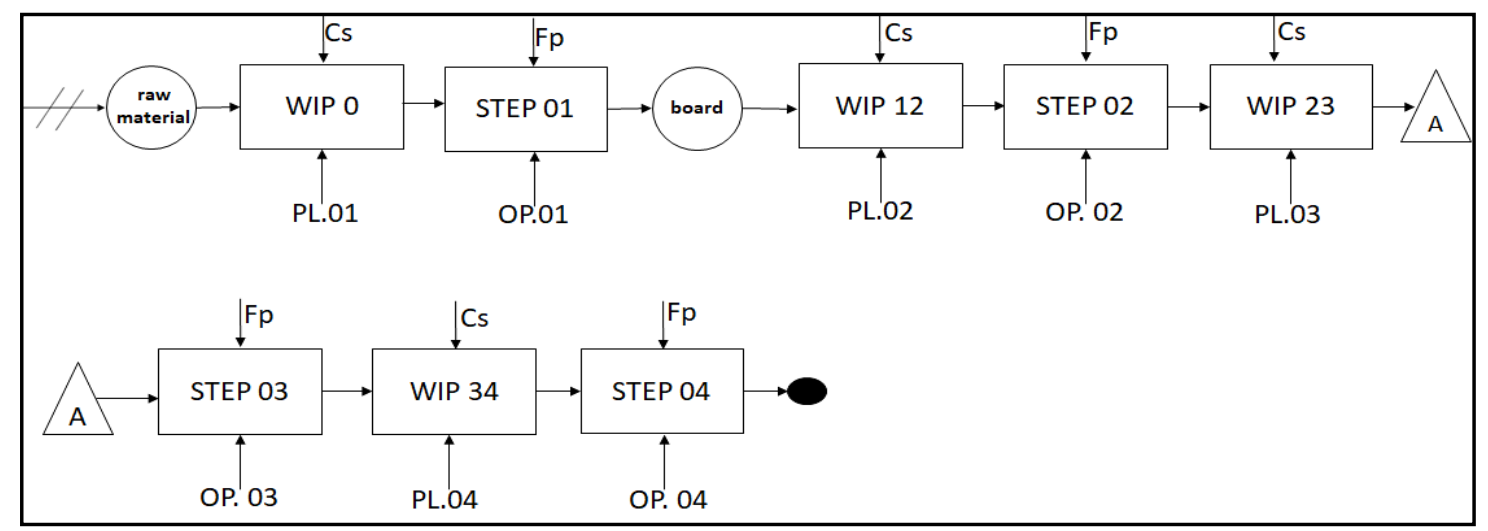

Figure 3: Conceptual model.

Thus, in the conception stage, the mapping technique proposed by [13] was applied to develop the conceptual model. Its validation was done by experts through the face-to-face technique. The next step was the input's modelling. To achieve this target, it was necessary to conduct an intense work of timing the steps of the line. Altogether, 1200 processing time values were collected throughout 9 months of data collection. Several stopwatches were used together with video cameras located on the ceiling above the production line for the measurements. It is essential to emphasize that the times measured on the first week; were all ignored because workers were at an out of normal production pace. This behavioural change can be attributed to the anxiety generated on employees by the stopwatch presence. It is also noteworthy that the data for each step were always collected from the same operator. Thus, variations in production times cannot be attributed to differences in operators' skills. The work shift was divided into four periods, as shown in Fig. 4, for creating the scenarios that will be presented.

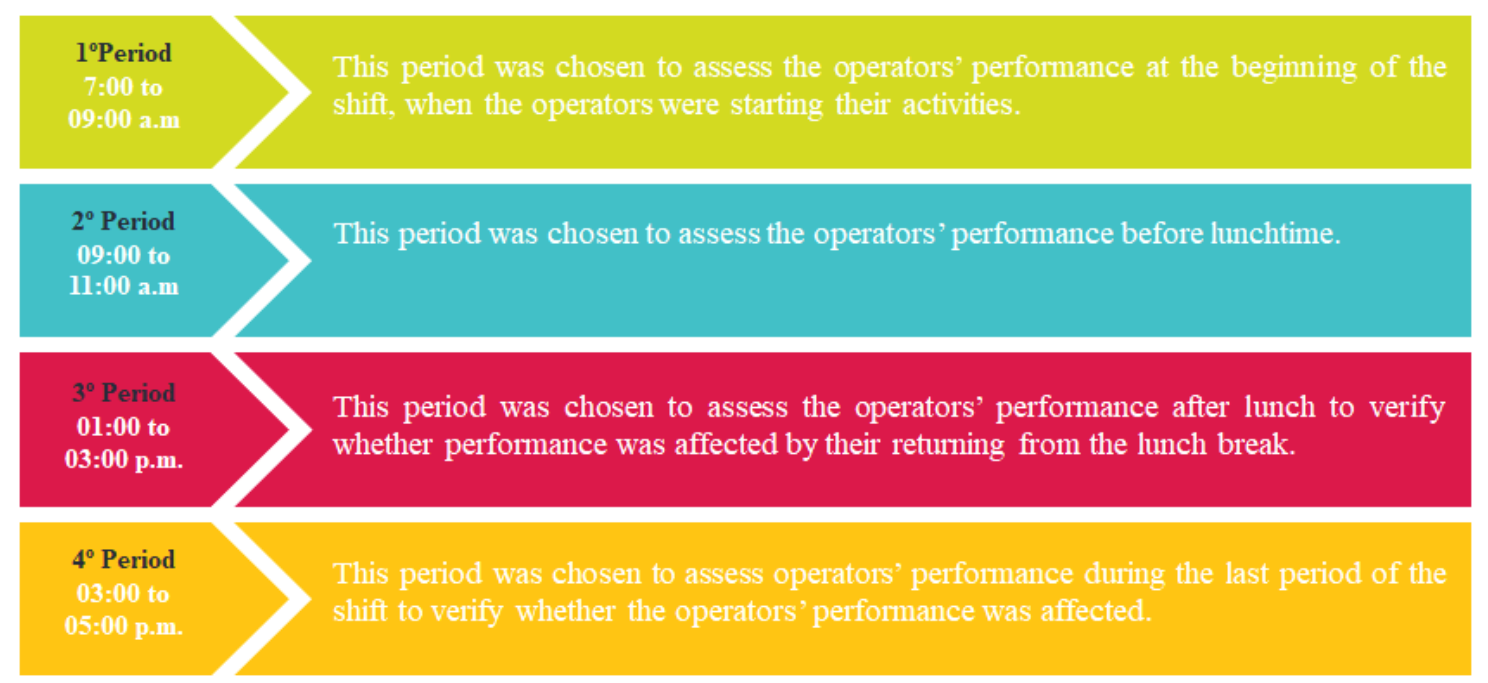

Figure 4: Division of periods. 
The processing times obtained through the chrono analysis of the steps were used to calculate several statistical distributions according to each period considered, as shown in Table I.

Table I: Statistical distributions.

\begin{tabular}{|c|c|c|c|c|}
\cline { 2 - 5 } \multicolumn{1}{c|}{} & Step 01 & Step 02 & Step 03 & Step 04 \\
\hline $1^{\text {st }}$ period & Triangular & Beta & Triangular & Weibull \\
\hline $2^{\text {nd }}$ period & Beta & Weibull & Power function & Pearson \\
\hline $3^{\text {rd }}$ period & Loglogistic & Beta & Triangular & Pearson \\
\hline $4^{\text {th }}$ period & Rayleigh & Weibull & Weibull & Beta \\
\hline
\end{tabular}

The quality of fit tests is calculated for each fitted distribution to determine the relative quality of fit [27-30]. The Anderson-Darling [31] test is performed to test the excellence of quality of fit of the fitted accumulative distribution to the input data. This test was applied for the discover of each statistical distribution in Table I.

In the implementation stage, the computational model was developed using ProModel ${ }^{\circledR}$ software, according to Fig. 5. The verification and validation tests were applied according to $[15,16]$.

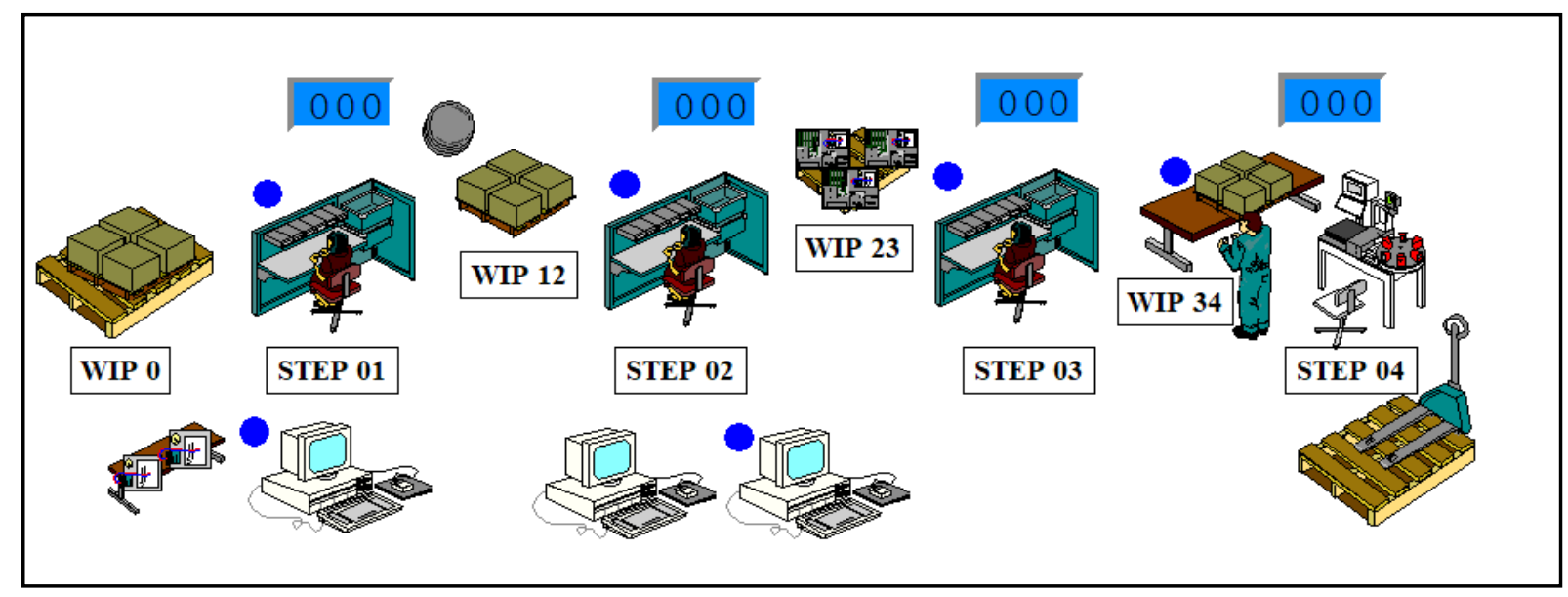

Figure 5: Computational model form ProModel ${ }^{\circledR}$.

The computational verification model was made mainly through debuggers in the software. In face of the statistical validation, the variable that was chosen was the total number of electronics boards produced over a week. The validation was made from the comparison of electronics boards made over a week using time analysis data and parts produced over a week during the same period throughout the real system $[15,16,25]$. When it comes to the work shift, seven scenarios have been developed. They are presented in Table II.

For each one of the seven scenarios in the work shift, it was initially performed thirty replications during the week. The primary number of replications was calculated in accordance with [16] and thirty replicates were made for each scenario, where the number of the output of the computer model refers to the total production throughout an entire week of production. For this study, a week was considered from Monday to Friday. It is noteworthy that real data were obtained over 30 consecutive weeks through the production control system of the company where this study was conducted. To run replicas operationally in this research, direct and manual data entry in the computational model [32] were used.

Finally, in the analysis stage, the scenarios were implemented. The first experiment involved the deterministic processing times which were named Scenario 1. Once the time was deterministic, it was not necessary to execute replications. The remaining experiments (other 
scenarios) performed in this study took into consideration stochastic processing times. Once the times were stochastic, the simulator was programmed to make 30 replications of the model depending on the probability distributions that were previously calculated [31].

Table II: The seven scenarios.

\begin{tabular}{|c|c|l|}
\hline Scenario & Type & \multicolumn{1}{|c|}{ Description } \\
\hline I & Deterministic & $\begin{array}{l}\text { For the entire shift, the times collected were used, counting on the } \\
\text { average standard time of five samples collected, independently of } \\
\text { the time of day, in the work shift. }\end{array}$ \\
\hline II & Stochastic & $\begin{array}{l}\text { For the entire shift, the times collected were used, counting on a } \\
\text { distribution of probability of ten samples that were collected, } \\
\text { independently of the time of day, during the work shift. }\end{array}$ \\
\hline III & Stochastic & During the whole shift, the distribution in the first period was used. \\
\hline IV & Stochastic & In the second period the distribution was used during the entire shift. \\
\hline V & Stochastic & In the third period the distribution was used during the entire shift. \\
\hline VI & Stochastic & In the fourth period the distribution was used during the entire shift. \\
\hline VII & Stochastic & $\begin{array}{l}\text { The corresponding probability distribution was used for each period } \\
\text { of the day. }\end{array}$ \\
\hline
\end{tabular}

\section{RESULTS AND DISCUSSION}

The first action was to analyse the output data of the seven scenarios, and the Dotplot was conceived using Minitab ${ }^{\circledR}$ (Fig. 6) to assess and compare a sample of the total number of electronics boards produced per week for each proposed scenario.

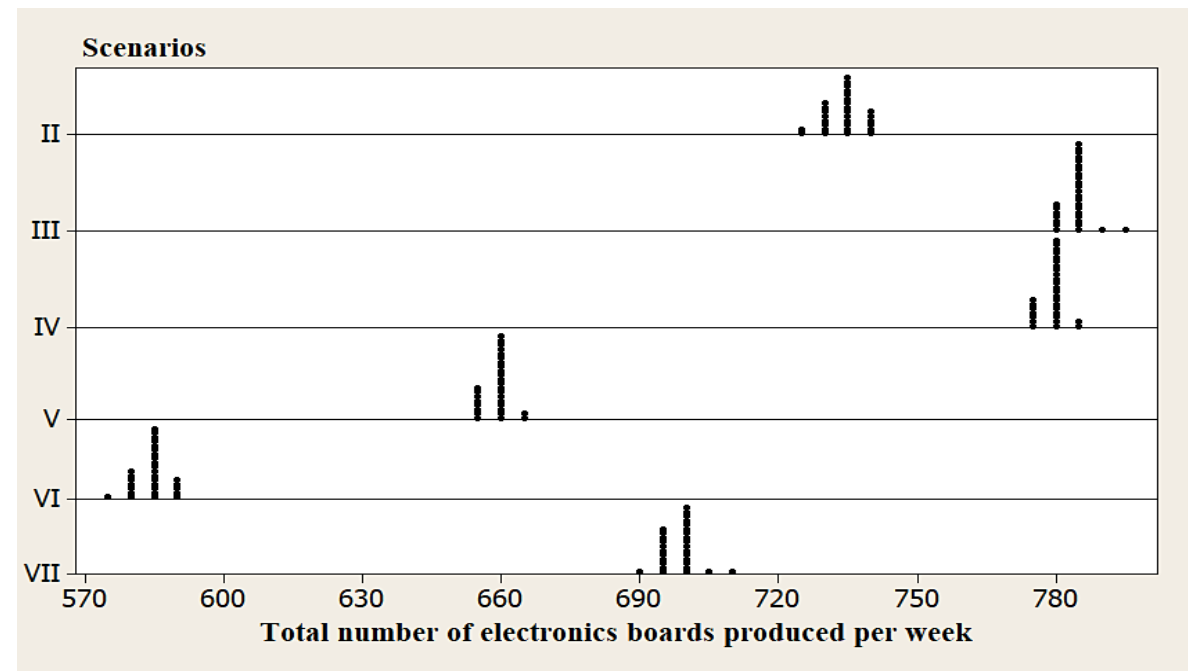

Figure 6: Dotplot of each scenario.

It is evident that Scenario VI presents the smallest quantity produced of the seven scenarios considered. It is worth mentioning that in Scenario VI the processing times were collected near the end of the shift. Therefore, through the Dotplot, an indication that the performance of the human factor varies during the work shift is observable.

Applying the classic definition of productivity (output divide by input) [33] and considering that the input is constant and equal to the operators on the assembly line, it is possible to build Table III. 
Table III: DES productivity.

\begin{tabular}{|c|c|c|}
\hline Scenario & $\begin{array}{c}\text { Mean produced per week } \\
(\boldsymbol{n}=\mathbf{3 0})\end{array}$ & $\begin{array}{c}\text { Productivity } \\
\text { (output/input) }\end{array}$ \\
\hline I & 783 & 196 \\
\hline II & 733 & 183 \\
\hline III & 784 & 196 \\
\hline IV & 778 & 195 \\
\hline V & 659 & 165 \\
\hline VI & 584 & 146 \\
\hline VII & 698 & 175 \\
\hline
\end{tabular}

For each proposed scenario, there is a specific productivity value. Notably, the scenarios that represent the return from lunch break (Scenario V) and the end of the shift (Scenario VI) have the lowest productivity values.

To apply the computational model validation, a test of statistics was firstly performed for the work shift to confirm the regularity of the total number of electronics boards produced. Assuming a confidence level of $95 \%$, the output samples for each scenario were considered not normally distributed, since their Anderson-Darling $p$-values are less than 0,05.

Thus, the output samples cannot be compared by parametric tests. From the observation of some premises - variable of interest is continuous, samples are independent and each individual in the population has an equal probability of being selected in the sample - another option had to be considered. For these situations, Montgomery and Runger [18] recommend MannWhitney tests. Table IV shows the outcomes of the Mann-Whitney tests used in the comparison between each scenario's outputs and the real systems.

Table IV: Mann-Whitney test.

\begin{tabular}{|c|c|}
\hline \multirow{2}{*}{ Scenario } & Test statistic \\
\cline { 2 - 2 } & Mann-Whitney $\boldsymbol{p}$-value \\
\hline I & $<0.05$ \\
\hline II & $<0.05$ \\
\hline III & $<0.05$ \\
\hline IV & $<0.05$ \\
\hline V & $<0.05$ \\
\hline VI & $<0.05$ \\
\hline VII & $>0.05$ \\
\hline
\end{tabular}

Based on the results presented in Table IV, and assuming a confidence level of $95 \%$, only Scenario VII was validated, since $p$-value $>0,05$.

Therefore, the most detailed scenario that used a probability distribution by each period was the only one that was validated in this context. This fact would be an indication that the performance of the human factor, in fact, affects the final result of computational validation in simulation projects situations where there is a large portion of manual activities.

\section{CONCLUSIONS}

This article presented a study of a manual assembly line and investigated the impact of human factor performance on the variation of work productivity and, therefore, on the validity of the computer model. 
According to the results of the Mann-Whitney statistical test, only Scenario VII was validated. This scenario was the most fractional, with four distributions of statistical probability per stage of production of the assembly line. In this Scenario VII, a stochastic distribution was used for each of the four periods of the work shift. Thus, the results show that human performance affects the productivity of the investigated assembly line, affecting the validation of the stochastic simulation.

Finally, this work identified that the validation of the computational model, using the statistical test presented, has a relationship with the performance variation of the human factor, which in this case was represented by the productivity of the assembly line, in accordance with the planned seven scenarios with their respective statistical probability distributions. Therefore, this research contributed to draw attention of users of computer simulation to the importance of considering human factors within a DES project using productivity as a comparative metric in the validation tests of the computational model.

It is worth mentioning that these partial conclusions are limited to the type of process studied in this work, which deals with an assembly line of electronic boards that works with high-volume production, in a process that rely on manual activities performed mostly by women. And finally, some suggestions for future works: analysis of the variation in the work rate over the days of the month, analysis of the variation in the rhythm of human work due to the anxiety generated by the proximity of the timekeeper, and an analysis considering not only physiological factors, but also psychological factors, as a predefined production goal.

\section{ACKNOWLEDGEMENTS}

The authors thank FAPEMIG and CNPq for their support.

\section{REFERENCES}

[1] Banks, J.; Carson, J. S.; Nelson, B. L.; Nicol, D. M. (2010). Discrete-event System Simulation, $5^{\text {th }}$ edition, Prentice-Hall, Upper Saddle River

[2] Law, A. M. (2019). How to build valid and credible simulation models, Proceedings of the 2019 Winter Simulation Conference, 1402-1414, doi:10.1109/WSC40007.2019.9004789

[3] Pereira, T. F.; Montevechi, J. A. B.; Miranda, R. de C.; Friend, J. D. (2014). Integrating soft systems methodology to aid simulation conceptual modelling, International Transactions in Operational Research, Vol. 22, No. 2, 265-285, doi:10.1111/itor.12133

[4] Baines, T.; Mason, S.; Siebers, P. O.; Ladbrook, J. (2004). Humans: the missing link in manufacturing simulation?, Simulation Modelling Practice and Theory, Vol. 12, No. 7-8, 515-526, doi:10.1016/S1569-190X(03)00094-7

[5] Siebers, P. O. (2007). Worker performance modeling in manufacturing systems simulation: proposal for an agent-based approach, Rennard, J. P. (Ed.), Handbook of Research on Nature Inspired Computing for Economics and Management, IGI Global, Hershey, 661-678

[6] Dinges, D. F.; Pack, F.; Williams, K.; Gillen, K. A.; Powell, J. W.; Ott, G. E.; Aptowicz, C.; Pack, A. I. (1997). Cumulative sleepiness, mood disturbance, and psychomotor vigilance performance decrements during a week of sleep restricted to 4-5 hours per night, Sleep, Vol. 20, No. 4, 267-277, doi:10.1093/sleep/20.4.267

[7] Dorrian, J.; Rogers, N. L.; Dinges, D. F. (2005). Psychomotor vigilance performance: neurocognitive assay sensitive to sleep loss, Kushida, C. A. (Ed.), Sleep Deprivation: Clinical Issues, Pharmacology and Sleep Loss Effects, Marcel Dekker Inc., New York, 39-70, doi: $10.3109 / 9780203998007-10$

[8] Harrison, Y.; Horne, J. A. (2000). The impact of sleep deprivation on decision making: a review, Journal of Experimental Psychology: Applied, Vol. 6, No. 3, 236-249, doi:10.1037/1076$\underline{898 x \cdot 6.3 .236}$ 
[9] Jay, S. M.; Lamond, N.; Ferguson, S. A.; Dorrian, J.; Jones, C. B.; Dawson, D. (2007). The dynamics of recovery sleep when recovery opportunity is restricted, Sleep, Vol. 30, No. 3, 353360, doi: $10.1093 / \mathrm{sleep} / 30.3 .353$

[10] Lamond, N.; Dawson, D. (2002). Quantifying the performance impairment associated with fatigue, Journal of Sleep Research, Vol. 8, No. 4, 255-262, doi:10.1046/j.1365-2869.1999.00167.x

[11] Mikulincer, M.; Babkoff, H.; Caspy, T.; Sing, H. (1989). The effects of 72 hours of sleep loss on psychological variables, British Journal of Psychology, Vol. 80, No. 2, 145-162, doi:10.1111/j.2044-8295.1989.tb02309.x

[12] Pilcher, J. J.; Hufcutt, A. I. (1996). Effects of sleep deprivation on performance: a meta-analysis, Sleep, Vol. 19, No. 4, 318-326, doi:10.1093/sleep/19.4.318

[13] Montevechi, J. A. B.; Leal, F.; de Pinho, A. F.; Costa, R. F.; de Oliveira, M. L. M.; Silva, A. L. F. (2010). Conceptual modeling in simulation projects by mean adapted IDEF: an application in a Brazilian tech company, Proceedings of the 2010 Winter Simulation Conference, 1624-1635, doi: 10.1109/WSC.2010.5678908

[14] Song, E.; Nelson, B. L.; Pegden, C. D. (2014). Advanced tutorial: input uncertainty quantification, Proceedings of the 2014 Winter Simulation Conference, 162-176, doi:10.1109/ WSC.2014.7019886

[15] Sargent, R. G. (2013). Verification and validation of simulation models, Journal of Simulation, Vol. 7, No. 1, 12-24, doi:10.1057/jos.2012.20

[16] Kleijnen, J. P. C. (1995). Theory and methodology: verification and validation of simulation models, European Journal of Operational Research, Vol. 82, No. 1, 145-162, doi:10.1016/03772217(94)00016-6

[17] Raunak, M.; Olsen, M. (2014). Quantifying validation of discrete event simulation models, Proceedings of the 2014 Winter Simulation Conference, 628-639, doi:10.1109/ WSC.2014.7019927

[18] Montgomery, D. C.; Runger, G. C. (2010). Applied Statistics and Probability for Engineers, $5^{\text {th }}$ edition, John Wiley \& Sons, Hoboken

[19] Digiesi, S.; Kock, A. A.; Mummolo, G.; Rooda, J. E. (2009). The effect of dynamic worker behavior on flow line performance, International Journal of Production Economics, Vol. 120, No. 2, 368-377, doi:10.1016/j.ijpe.2008.12.012

[20] Sena, D. C.; Silva, E. M. M.; Costa, A. P. R.; Montevechi, J. A. B.; Pinho, A. F.; Miranda, R. C. (2017). Dynamic allocation of additional human resources using hybrid simulation, International Journal of Simulation Modelling, Vol. 16, No. 1, 84-95, doi:10.2507/ijsimm16(1)7.371

[21] Brailsford, S. C. (2014). Modeling human behavior - an (id)entity crisis?, Proceedings of the 2014 Winter Simulation Conference, 1539-1548, doi:10.1109/WSC.2014.7020006

[22] Oliveira, M. L. M.; Montevechi, J. A. B.; Pinho, A. F.; Miranda, R. C. (2017). Using hybrid simulation to represent the human factor in production systems, International Journal of Simulation Modelling, Vol. 16, No. 2, 263-274, doi:10.2507/ijsimm16(2)7.378

[23] Son, Y.-J.; Kim, S.; Xi, H.; Mungle, S. (2013). An extended BDI model for human behaviors: decision-making, learning, interactions, and applications, Proceedings of the 2013 Winter Simulations Conference, 401-411, doi:10.1109/WSC.2013.6721437

[24] Spencer, M. B. (1987). The influence of irregularity of rest and activity on performance: a model based on time since sleep and time of day, Ergonomics, Vol. 30, No. 9, 1275-1286, doi: $10.1080 / 00140138708966022$

[25] Leal, F.; Costa, R. F. de S.; Montevechi, J. A. B.; de Almeida, D. A.; Marins, F. A. S. (2011). A practical guide for operational validation of discrete simulation models, Pesquisa Operacional, Vol. 31, No. 1, 57-77, doi:10.1590/S0101-74382011000100005

[26] Miranda, R. de C.; Paiva, C. N.; Montevechi, J. A. B.; Pereira, T. F. (2017). Human factors in an automotive discrete event simulation model, Acta Scientiarum. Technology, Vol. 39, No. 5, 615622, doi:10.4025/actascitechnol.v39i5.30446

[27] Breiman, L. (1973). Statistics: With a View Toward Applications, Houghton Mifflin Co., Boston

[28] Law, A. M.; Kelton, W. D. (2000). Simulation Modeling and Analysis, $3^{\text {rd }}$ edition, McGraw-Hill, New York

[29] Banks, J.; Carson, J. S. (1984). Discrete-Event System Simulation, $1^{\text {st }}$ edition, Prentice-Hall, Englewood Cliffs 
[30] Kendall, M. G.; Stuart, A.; Ord, J. K. (1987). Kendall's Advanced Theory of Statistics, $5^{\text {th }}$ edition, Oxford University Press, New York

[31] Anderson, T. W.; Darling, D. A. (1954). A test of goodness of fit, Journal of the American Statistical Association, Vol. 49, No. 268, 765-769, doi:10.1080/01621459.1954.10501232

[32] Robertson, N.; Perera, T. (2002). Automated data collection for simulation?, Simulation Practice and Theory, Vol. 9, No. 6-8, 349-364, doi:10.1016/S0928-4869(01)00055-6

[33] Chatman III, V. V. (1995). Change-points: a proposal for software productivity measurement, Journal of Systems and Software, Vol. 31, No. 1, 71-91, doi:10.1016/0164-1212(94)00088-5 